\title{
Near-surface mean circulation and kinetic energy in the central North Atlantic from drifter data
}

\author{
Bernd Brügge \\ Institut für Meereskunde, Kiel, Germany
}

\begin{abstract}
An analysis of a large drifting buoy data set is presented. The objective is to obtain a self-contained description of the properties of the near-surface circulation (drogue depth $100 \mathrm{~m}$ ) in the central North Atlantic Ocean, independent of hydrographic data. A necessary preanalysis step was the removal of all data from undrogued buoys from the data set. The physical parameters of the circulation were deduced by averaging the remaining data in $2^{\circ} \times 3^{\circ}$ boxes. The minimum amount of data which is necessary to get statistically stable results was determined by an empirical quality criterion. All important mean currents in the investigation area are reproduced by the near-surface mean velocity field. A separation of the mean velocity field into a nondivergent and an irrational part shows that the flow field is almost nondivergent. The distribution of eddy kinetic energy is concentrated along the mean currents and provides the largest part of the total kinetic energy, but there are regional variations. Energy from inertial movements dominates the high-frequency part of the kinetic energy. Its distribution is very patchy. The analysis of the Reynolds stress terms shows an energy transfer from the eddy field to the mean circulation in the vicinity of the North Atlantic Current.
\end{abstract}

\section{Introduction}

Most of the published circulation schemes of the North Atlantic are based on hydrographic data. $S y$ [1987] outlined the historical development of the knowledge about the nearsurface circulation. Despite the huge amount of data no general picture has been developed. In the mid-1970s two contrary views existed. Dietrich et al. [1975] drew the "classical" picture of the circulation, that is, a separation of the Gulf Stream near Newfoundland into two branches heading toward the north and the southeast, respectively, and being direct continuations of the Gulf Stream. On the other hand, Worthington [1976] presented the so-called "two gyre" hypothesis stating that the Gulf Stream and the North Atlantic Current form the western flanks of two separated large-scale gyres in the western North Atlantic. Although several investigations showed that none of the schemes could be confirmed [e.g., Clarke et al., 1980; Krauss, 1986; Sy, 1988]. Schmitz and McCartney [1993] recently published a slightly modified Worthington scheme. This indicates that the discussion about basic properties of the mean current field in the North Atlantic is still ongoing.

One method used to get more insight into the circulation picture are direct Lagrangian current measurements with satellite-tracked drifting buoys. Drifters can provide basin wide information about the circulation and its variability with a high spatial and temporal resolution. In the 1980s, two publications, among others, based on drifter data already dealt with that topic. Richardson [1983] compiled a data set of 110 drifting buoys and prepared maps of mean velocity and eddy kinetic energy on a $2^{\circ} \times 2^{\circ}$ grid between $20^{\circ} \mathrm{N}$ and $50^{\circ} \mathrm{N}$. Because all buoys were deployed in the Gulf Stream most of the measurements were taken in the western part. On the basis of data from 62 buoys launched by the Institut für Meereskunde (IfM),

Copyright 1995 by the American Geophysical Union.

Paper number 95JC01501.

0148-0227/95/95JC-01501\$05.00
Kiel, Germany, which are a subset of the data set available now (see next section), Krauss and Käse [1984] presented a similar approach in approximately the same latitude band but more concentrated to the central and eastern part of the North Atlantic.

There are two main reasons that motivated us to perform a new analysis of the mean circulation and the kinetic energy distribution in the North Atlantic. First, in both papers cited above the drifter data were used in a rather uncritical way, that is, all available data were used without any attention to the drogue's state. The investigations of Krauss et al. [1989] and Brügge and Dengg [1991] showed that this is a very important feature influencing the quality of a drifter data analysis considerably. They stated that the separation of data from drogued and undrogued buoys is essential in order to get reliable results. Second, the IfM data set had grown substantially since the completion of the work done by Krauss and Käse [1984]. Hence a qualitative and quantitative improvement could be expected from a new analysis. Improvements are the elimination of data from undrogued buoys which prevents a contamination of the results by direct wind influence on the drifting buoys, a better statistical significance, and an expansion of the analysis to a larger geographical region and to topics not considered before.

The data set and its statistical treatment is presented in section 2. The properties of the mean circulation and the kinetic energy distribution are discussed in sections 3 and 4, respectively. A summary and concluding remarks are given in section 5 .

\section{Data Set and Method}

Within the framework of the Kiel "Warmwassersphäre" project 199 satellite-tracked drifting buoys have been deployed in the North Atlantic Ocean from 1981-1989. Two buoy types with very similar specifications were used: 160 buoys were of the HERMES type and 39 were of the CEIS type. All drifters 


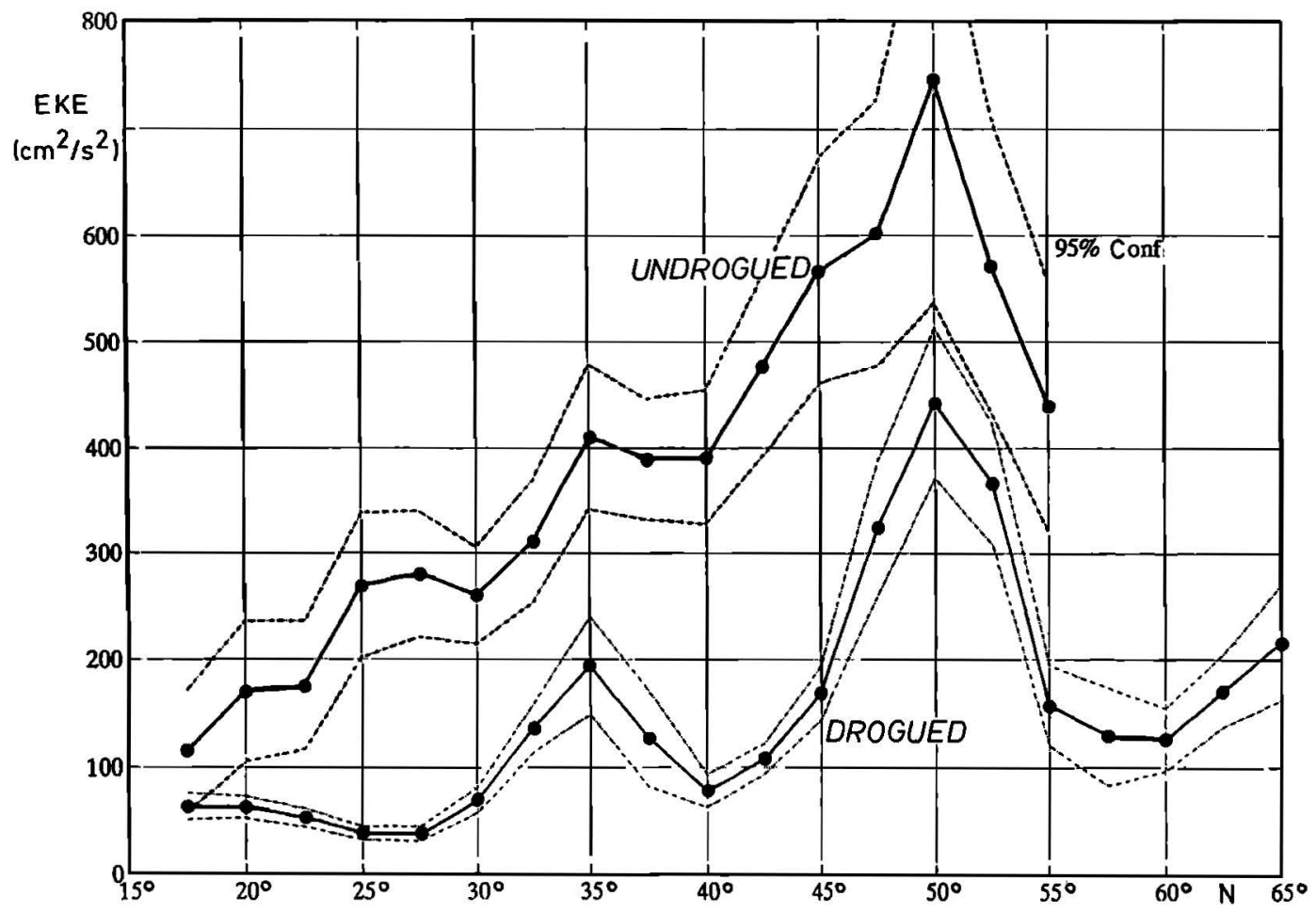

Figure 1. Eddy kinetic energy (EKE) along $30^{\circ} \mathrm{W}$ between $15^{\circ} \mathrm{N}$ and $65^{\circ} \mathrm{N}$ in the North Atlantic $\left(5^{\circ} \times 5^{\circ}\right.$ boxes) for drogued (depth $100 \mathrm{~m}$ ) and undrogued buoys.

had a window shade drogue at $100 \mathrm{~m}$ depth in order to measure the geostrophic flow. The drogue to buoy cross area ratio is about 35. A detailed description of the buoy types and the buoy-drogue configuration is given by Krauss et al. [1989]. They found that the buoy-drogue system used here is a good current measuring device. Slippage is negligible to wind speeds less than $15 \mathrm{~m} / \mathrm{s}$, and it is less than $2 \mathrm{~cm} / \mathrm{s}$ under gale conditions. These results are confirmed by a recent investigation of Krauss [1995b]. He analyzed the combined effect of wind drag and Ekman currents on buoys drogued in $100 \mathrm{~m}$ depth. Because of the increased drag on the tether the slippage is slightly larger than the slippage of buoys drogued within the mixed layer but is less than $2 \mathrm{~cm} / \mathrm{s}$ in $90 \%$ of all cases.

The drifters were monitored by the Argos system providing typically 4-10 good locations per day. To produce equally spaced time series for each buoy, the raw data were subjected to a probability check and interpolated to 3-hour intervals using a three-point Lagrangian scheme. The data set comprises 66,363 buoy days and covers most of the North Atlantic [Brügge, 1993].

An essential precondition for a successful derivation of the geostrophic flow field is the elimination of data from undrogued drifters from the data set. This was realized using the method described by Brügge and Dengg [1991]. They demonstrated that retaining data of drifting buoys which had already lost their sails can lead to severe misinterpretations. Data from undrogued buoys yield higher mean and rms velocities than observed in reality and can blur real structures in the ocean. Independent of the investigation of Brügge and Dengg [1991], Figure 1 supports the importance of this preanalysis step. Two meridional eddy kinetic energy (EKE) sections are depicted which were deduced by averaging data from drogued and undrogued drifters in $5^{\circ} \times 5^{\circ}$ boxes along $30^{\circ} \mathrm{W}$. It is clearly visible that EKE is highly overestimated by undrogued drifters. The difference to the values from drogued buoys is significant with respect to the $95 \%$ confidence intervals. In addition, in the undrogued case a steady increase in EKE from the subtropics to the North Atlantic Current (NAC) is suggested, whereas the drogued data show a distinct minimum between the signal of the Azores Current (AC) at $35^{\circ} \mathrm{N}$ and the NAC.

Retaining data from drogued buoys only, the data set has been reduced to 34,339 buoy days which is $51.7 \%$ of its original size. The remaining trajectories are shown in Figure 2. Despite the considerable but indispensable data reduction the central North Atlantic is fairly well covered with buoy tracks. The only exceptions are the centers of the subtropical gyre and the subpolar gyre. With respect to quality, size, and spatialtemporal coverage this corrected data set is the most comprehensive base for quasi-Lagrangian studies of the near-surface circulation in the North Atlantic up to now. The only other comparable data set is the one compiled by Richardson [1983] which includes 110 drifting buoys with 20,000 buoy days.

All properties of the near-surface circulation which will be discussed in the following sections were deduced by averaging the data in geographical boxes. The resulting values represent spatial-temporal averages over the box area and the period during which drifter data were available in the box. When using this method, two aspects have to be considered that are contrary to each other. On the one hand, a fine geographical resolution is desired, that is, the box size should be as small as possible. On the other hand, it must be ensured that there are enough data in the box to get statistically reliable results. So the next important step before continuing the analysis is the determination of the minimum number of data per box, which in turn allows for a proper choice of the box size. Of course, 


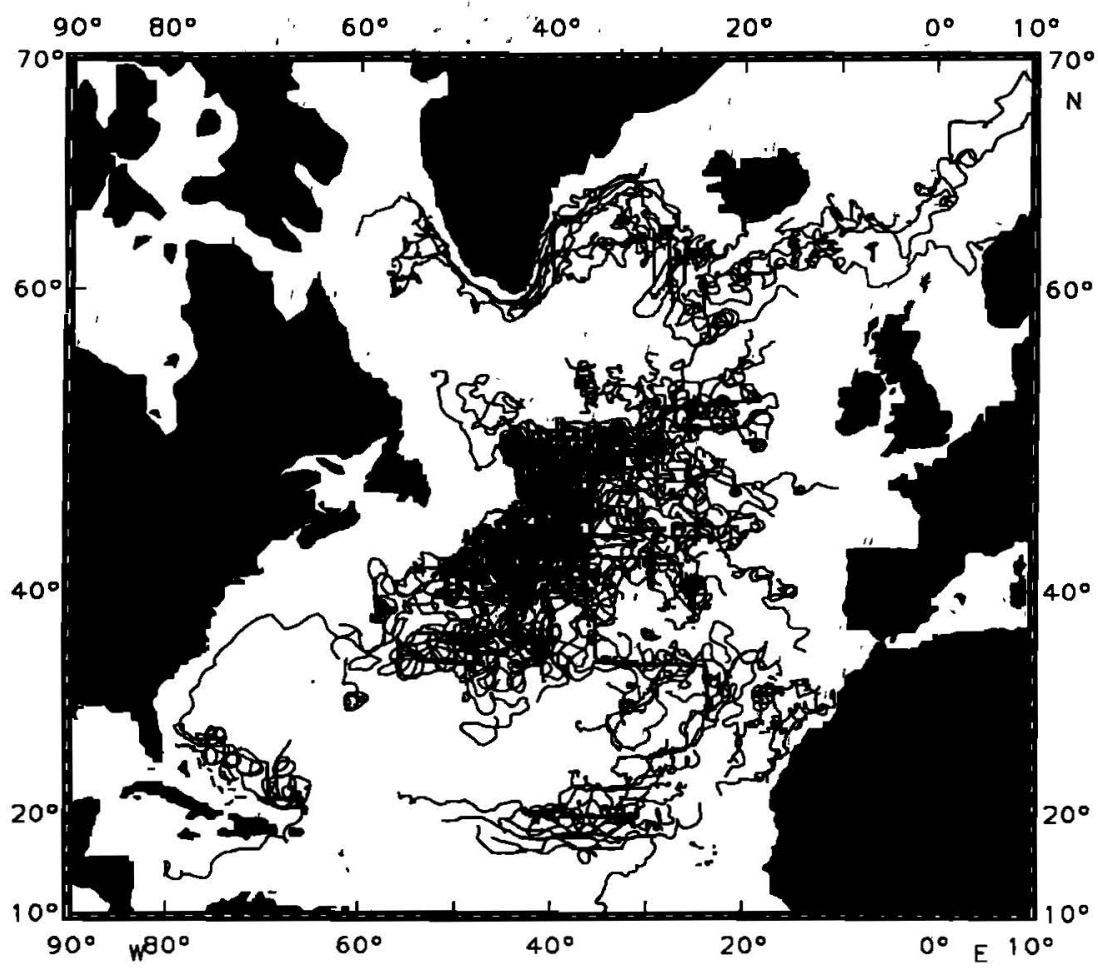

Figure 2. Trajectories of the Kiel drifting buoy data set in the North Atlantic (drogue depth $100 \mathrm{~m}$ ) after elimination of all buoys without drogues.

this is strongly dependent on the amount and the geographical distribution of the drifter data.

A study of the literature is not very helpful for solving this problem, because the cited values for the minimum number of data per box vary between 3 [Large and van Loon, 1989] and 125 buoy days [Krauss, 1986]. Some authors do not make any statements at all [e.g., Patterson, 1985; Piola et al., 1987]. There is just one common feature: If a minimum number of data per box is mentioned, it is constant for all boxes of the particular investigation.

A principal way to overcome this problem is the use of Lagrangian statistics. Like in "normal" statistics the error of the mean velocity is dependent on the variance, that is, on the kinetic energy level and on the number of data. The only difference is that successive velocity samples are not independent; that is, Lagrangian drifters "remember" their path for a certain period which is called the Lagrangian integral time scale. Given a certain error value, it is possible to determine the minimum number of data per box. Because of the variance dependence this value ean be different for each box. Thus Lagrangian statistics states that there is no point in using a fixed value in regions with heterogeneous kinetic energy distributions.

In practice, however, it was not possible to use this method because the amount of data needed to meet the requirements of the Lagrangian statistics is too high. Despite its large size our data set would only be sufficient for a coarse partition of the central North Atlantic if, for instance, an accuracy of \pm 1 $\mathrm{cm} / \mathrm{s}$ is desired for mean velocities. In that case, the dimensions of the boxes would be considerably bigger than the typical horizontal scales of the surface currents, so that the results would be questionable.

Therefore we adopted an empirical way to obtain a criterion for the minimum number of data per box. Keeping in mind that already Colin de Verdiere [1983, p. 381] stated that "the convergence of the mean values looks more encouraging than indicated by statistical principles" the criterion should be determined by the convergences of values observed in practice. At the same time the criterion should also, in agreement with Lagrangian statistics, depend on the kinetic energy level. For that purpose, cumulative means of the drift velocity and its variance were inspected in different regions of the North Atlantic using various box sizes. An example is depicted in Figure 3. It shows the corresponding values computed for a $2^{\circ} \times 3^{\circ}$ box located at $46^{\circ} \mathrm{N}-48^{\circ} \mathrm{N}, 38^{\circ} \mathrm{W}-41^{\circ} \mathrm{W}$. Because the sequence of the data, normally provided by the buoy trajectories, is not important for the box mean values it was rearranged 10 times by using a random number generator and plotted as a curve ensemble in order to get a better insight into the stability behavior. The box contains more than 250 buoy days, and the Lagrangian statistics provided a mean drift velocity of $19.8 \pm$ $6.8 \mathrm{~cm} / \mathrm{s}$ (Figure 3a) and a variance of $1462 \pm 368 \mathrm{~cm}^{2} / \mathrm{s}^{2}$ (Figure $3 \mathrm{~b}$ ). These errors are indicated by the bars at the final values. For their calculation a Lagrangian integral time scale of 2.5 days was assumed which is a mean of the values calculated by Krauss and Böning [1987]. It is clearly visible that Colin de Verdiere's statement is true for this example. The cumulative values of mean velocity as well as of kinetic energy are considerably more stable than indicated by the error bars.

Finally, the following empirical quality criterion was applied: the number of data in a box was considered sufficient if the variations of the variance curve ensemble did not exceed $\pm 5 \%$ of the final value. In the example this range is represented by the dashed lines (Figure 3b). Here the quality criterion is nearly met after about 90 buoy days and completely met after 180 buoy days. As already stated, the minimum number of data 

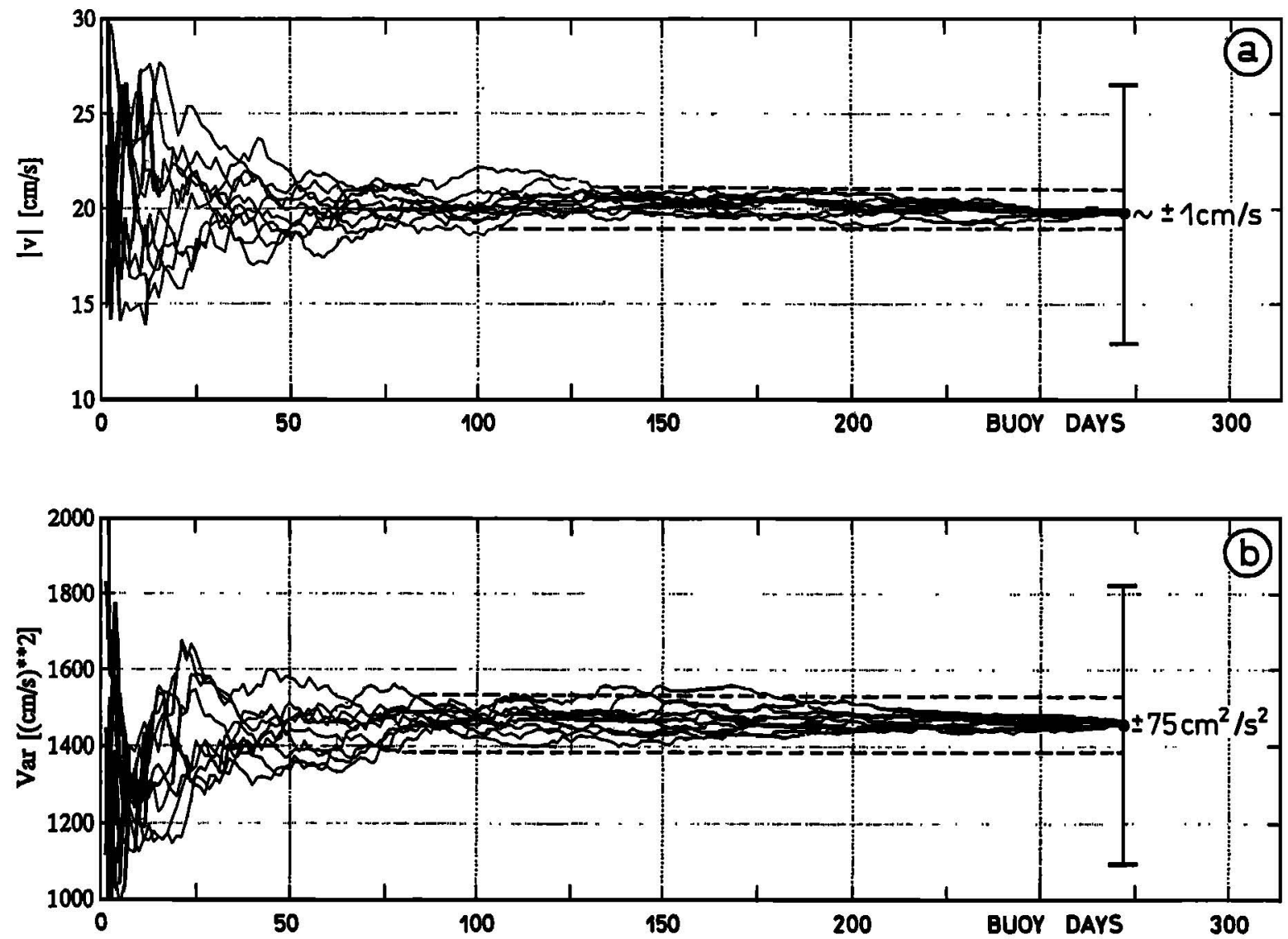

Figure 3. Curve ensembles of the cumulative means of (a) the velocity $(\mathrm{cm} / \mathrm{s})$ and (b) its variance $\left(\mathrm{cm}^{2} / \mathrm{s}^{2}\right)$ in a box extending from $46^{\circ} \mathrm{N}$ to $48^{\circ} \mathrm{N}$ and $38^{\circ} \mathrm{W}$ to $41^{\circ} \mathrm{W}$. Dashed lines represent a range of $\pm 1 \mathrm{~cm} / \mathrm{s}$ of the end values in Figure 3a and a range of $\pm 75 \mathrm{~cm}^{2} / \mathrm{s}^{2}$ of the end values in Figure 3b. Error bars indicate the $95 \%$ confidence intervals.

was determined in this way for many boxes. All of them contained data from more than one drifter. Values of boxes with equal energy level were averaged. The result was a functional relation between the minimum number of buoy days $A_{\text {dat }}$, which is necessary to meet the quality criterion, and the kinetic energy level $E_{\mathrm{km}}$ :

$$
A_{\text {dat }}=-0.00006 E_{\mathrm{kin}}^{2}+0.189 E_{\mathrm{kin}}+8.84 ; \quad r=0.997
$$

It is depicted in Figure 4. Its validity is confined to the range between the bounds indicated in the plot, that is, (1) even in areas with a very low energy level it is not possible to reach a stable level with less than 25 buoy days and (2) for kinetic energy levels $>1500 \mathrm{~cm}^{2} / \mathrm{s}^{2}$ a constant number of 160 buoy days is assumed. Different box sizes are implicitly taken into account by this quality criterion because a change in box size also changes both the spatial (and perhaps the temporal) variability and the energy level. All cases showed that the uncertainty in the mean velocities is less than $\pm 1 \mathrm{~cm} / \mathrm{s}$ if the criterion is satisfied.

With regard to this criterion the best compromise between geographical resolution and sufficient data density for our data set was to average the data in $2^{\circ} \times 3^{\circ}(\Delta \phi \times \Delta \lambda)$ boxes. Figure 5 shows the number of buoy days per box for those boxes which were used to calculate the parameters discussed below. Boxes in which the quality criterion could not be satisfied were rejected. In some regions more than 300 buoy days per box are available; in the NAC area, 200 buoy days per box are ex- ceeded everywhere. Additionally, the application of the criterion excluded areas with large spatial data density gradients from the analysis. The remaining Lagrangian sampling bias [Davis, 1991; Owens, 1991] does not exceed the uncertainty of the mean velocity estimates mentioned above.

\section{Mean Circulation}

Displayed in Figure 6a is a vector plot of the mean velocities representing the $2^{\circ} \times 3^{\circ}$ box averages. In order to reduce the influence of the arbitrarily chosen grid origin and to improve the resolution, especially in regions with sharp gradients, values for overlapping boxes which were shifted half a box size were computed. This resulted in 845 mean velocity vectors.

A schematic overview of Figure $6 \mathrm{a}$ is given in Figure $6 \mathrm{~b}$. The Gulf Stream extension is not completely covered by this data set. According to Clarke et al. [1980] the branching of the Gulf Stream (GS, indicated by a bold arrow in Figures $6 \mathrm{a}$ and $6 \mathrm{~b}$ ) occurs at $40^{\circ} \mathrm{N}, 46^{\circ} \mathrm{W}$, Mann [1967] found it at $38.5^{\circ} \mathrm{N}, 44^{\circ} \mathrm{W}$. Part of the water masses that the GS transports into this area recirculates south of $38^{\circ} \mathrm{N}$ and west of $50^{\circ} \mathrm{W}$. The other part feeds the North Atlantic Current (NAC) and is a direct continuation of the GS to the north. In the area $43^{\circ} \mathrm{N}-52^{\circ} \mathrm{N}$, $40^{\circ} \mathrm{W}-48^{\circ} \mathrm{W}$ the mean velocities generally exceed $10 \mathrm{~cm} / \mathrm{s}$ and reach maximum values of $25 \mathrm{~cm} / \mathrm{s}$. Analysis of single trajectories reveal drift speeds up to $150 \mathrm{~cm} / \mathrm{s}$ in the NAC core. The loop at the northwest corner $\left(53^{\circ} \mathrm{N}, 46^{\circ} \mathrm{W}\right)$ is well reproduced. 
However, not all the water circulates that way. The current vectors at about $47^{\circ} \mathrm{N}, 40^{\circ} \mathrm{W}$ indicate that there is a northeastward directed path, too. Krauss [1986] states that buoys deployed on the cold side of the NAC tend to stay in the NAC core for a longer time and to follow the course of the Subarctic Front (SAF). Buoys deployed on the warm side of the NAC leave it earlier, entering the associated eddy field. On the basis of hydrographic data, Krauss et al. [1987] found a branching of the NAC at $47^{\circ} \mathrm{N}, 41^{\circ} \mathrm{W}$ to be a transient feature. Their dynamic topography pattern shows extended high-pressure cells on the eastern flank of the NAC, indicating that a part of the water recirculates there. This recirculation is barely visible in our mean field.

East of $35^{\circ} \mathrm{W}$ the area north of $50^{\circ} \mathrm{N}$ belongs to the NAC regime. The current vectors possess a northward component. Influence of the subtropical gyre is perceptible south of $45^{\circ} \mathrm{N}$, while the region between $45^{\circ} \mathrm{N}$ and $50^{\circ} \mathrm{N}$ (marked by the dashdotted lines in Fig $6 \mathrm{~b}$ ) represents a transition zone between both regimes. This is supported by the almost eastward directed mean currents reaching $5-10 \mathrm{~cm} / \mathrm{s}$. Strongly variable NAC branches can be found there [Sy, 1988; Arhan, 1990; Sy et al., 1992]. According to Krauss [1986] the transition zone is located farther to the south, that is, between $42^{\circ} \mathrm{N}$ and $45^{\circ} \mathrm{N}$. The discrepancy in this analysis can be explained by the influence of the prevailing southwesterly winds on drifting buoys with detached drogues, suggesting a fictitious southward extension of the NAC area which is not consistent with reality.

The permanent branch of the NAC associated with the SAF turns to the northeast at about $28^{\circ} \mathrm{W}$. Because of data gaps its continuation beyond $55^{\circ} \mathrm{N}$ and $25^{\circ} \mathrm{W}$ is only incompletely reproduced. There the mean velocities drop below $10 \mathrm{~cm} / \mathrm{s}$.

North of the NAC the cyclonic circulation of the subpolar gyre is visible. It consists of a relatively weak Irminger Current (IC) which strengthens along its path to about $65^{\circ} \mathrm{N}, 35^{\circ} \mathrm{W}$ where it enters the strong East Greenland Current (EGC). The

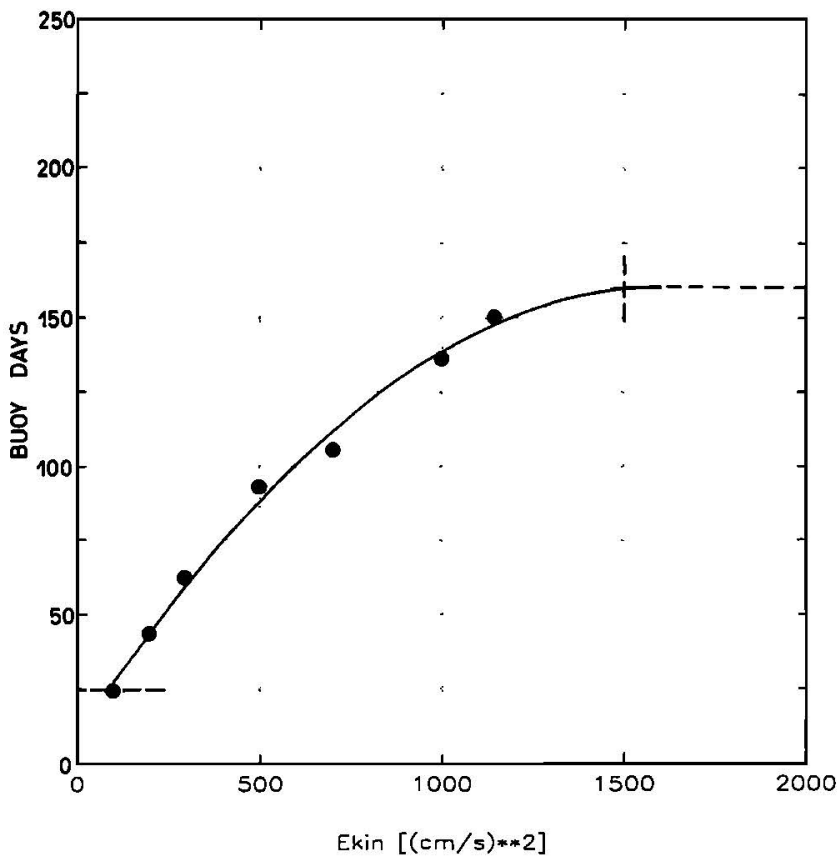

Figure 4. Relationship between the minimum number of buoy days per box ( $\left.A_{\text {dat }}\right)$ necessary to arrive at (almost) stable results and the kinetic energy in the box $\left(E_{\mathrm{k} ! n}\right)$.

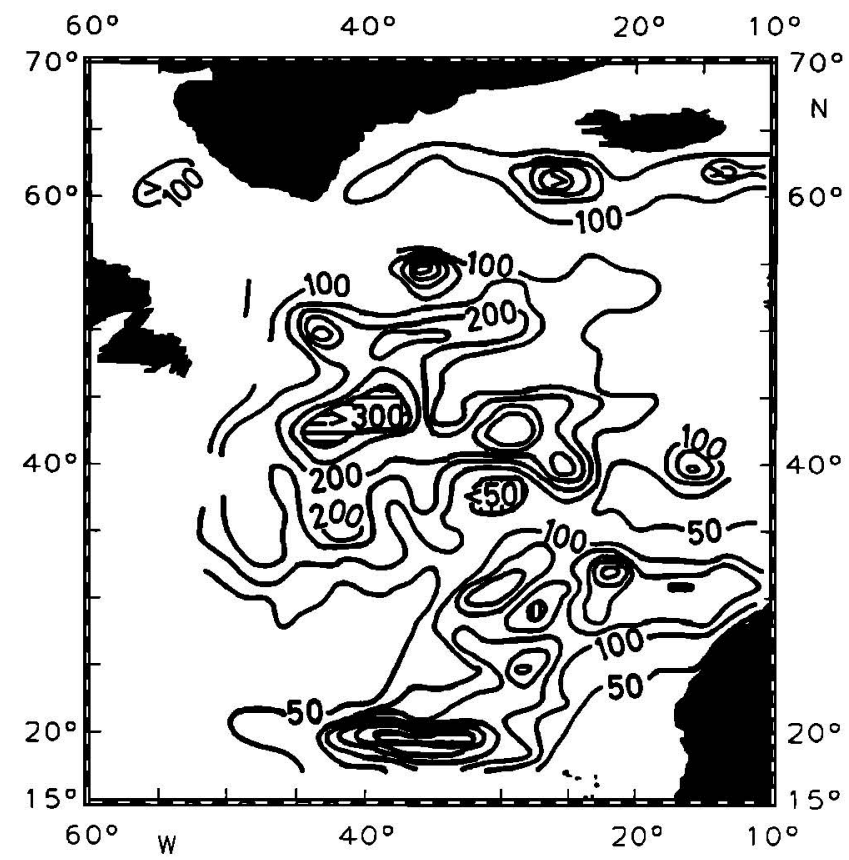

Figure 5. Number of buoy day days available for each $2^{\circ} \times 3^{\circ}$ box. Contour interval is 50 buoy days. Areas $>300$ buoy days per box are horizontally hatched, areas $<50$ buoy days are vertically hatched.

intensity of the EGC increases from north to south and toward the coast, exceeding mean velocities of $20 \mathrm{~cm} / \mathrm{s}$. West of Cape Farewell the West Greenland Current (WGC) shows a similar behavior. In the Labrador Sea the circulation agrees well with the "classical" pictures [e.g., Sverdrup et al., 1942]. A complete reproduction of the Labrador Current (LC) is limited by the sparse database in that area. Very weak and partly nonsignificant mean velocities can be found in the center of the gyre. The separation between the subpolar gyre and the NAC is situated above the Reykjanes Ridge. Inspection of trajectories in that area [Krauss, 1995a] clearly reveals that buoys deployed off the eastern flank of the ridge first move toward the south and then continue toward the Iceland-Faroe Ridge, whereas those deployed west of $28^{\circ} \mathrm{W}$ head toward the Denmark Strait.

The area from about $41^{\circ} \mathrm{N}-43^{\circ} \mathrm{N}$ and $42^{\circ} \mathrm{W}-45^{\circ} \mathrm{W}$ is covered by an anticyclone as described by Mann [1967]. Its northeastern branch feeds the Azores Current $(A C)$ at $35^{\circ} \mathrm{N}, 35^{\circ} \mathrm{W}$. Another source of the AC originates in the GS extension and runs through a cyclonic loop at $34^{\circ} \mathrm{N}, 50^{\circ} \mathrm{W}$. The $\mathrm{AC}$ itself stands out as a zonal band between $33^{\circ} \mathrm{N}$ and $35^{\circ} \mathrm{N}$ with mean velocities up to $10 \mathrm{~cm} / \mathrm{s}$ against its background with $2-4 \mathrm{~cm} / \mathrm{s}$. At least two branches, one of them is the Canary Current (CC), enter the North Equatorial Current (NEC). A third branch at $30^{\circ} \mathrm{N}, 35^{\circ} \mathrm{W}$ as described by Klein and Siedler [1989] is not detectible because of the sparse data coverage in that region. However, the position of the $\mathrm{AC}$ and the other branches agree well with their results which are based on historical hydrographic data.

South of $25^{\circ} \mathrm{N}$ the NEC looks very similar to the classical pictures [e.g., Schott, 1944]. Mean velocities increase from north to south and from east to west up to values of about 15 $\mathrm{cm} / \mathrm{s}$. Nothing can be said about the existence and the properties of the Portugal Current because there are no data in that area. 

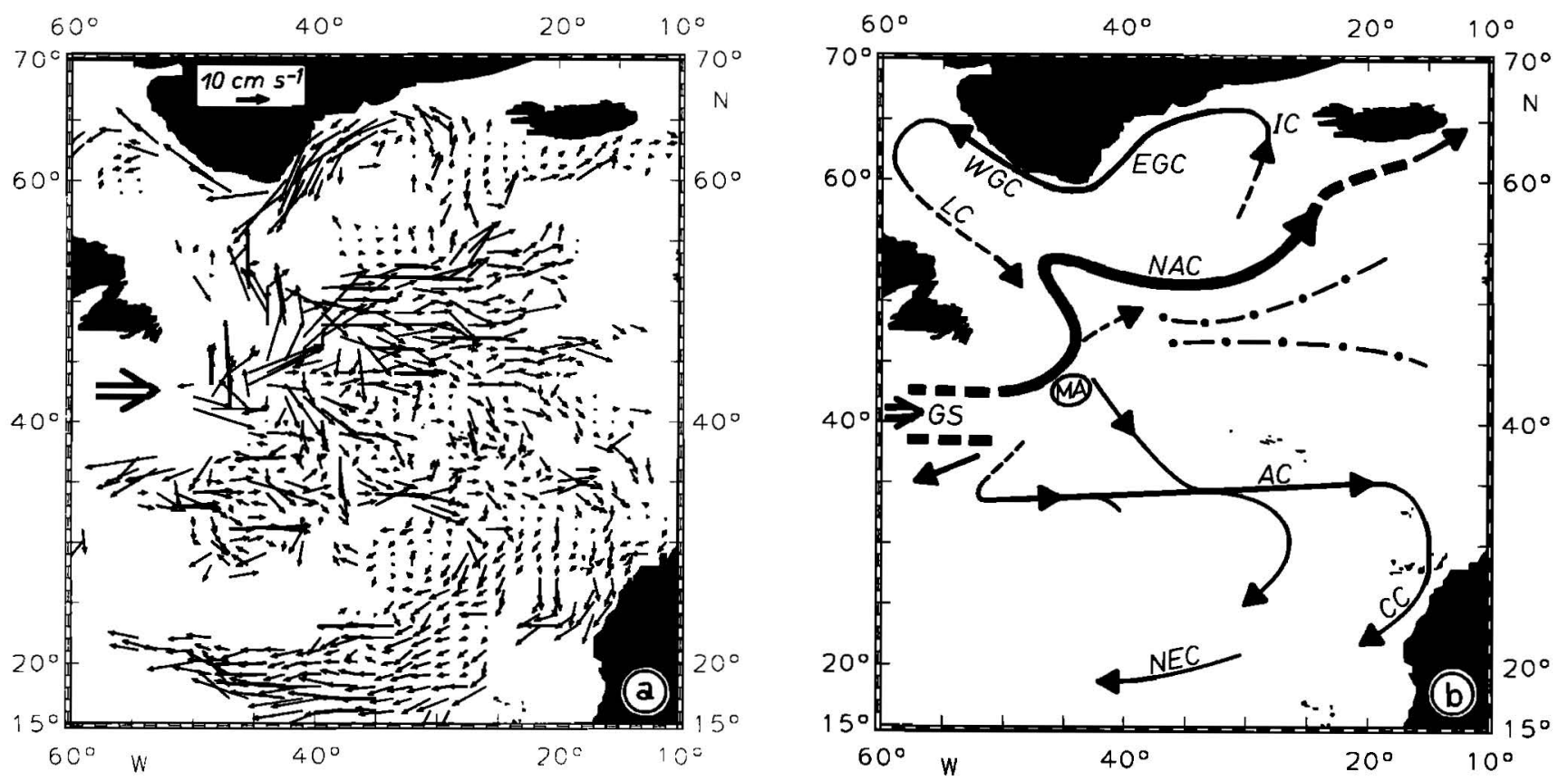

Figure 6. (a) Vector plot of the mean circulation in $100 \mathrm{~m}$ depth deduced from box averages. (b) Schematic representation of Figure 6a. Abbreviations are explained in the text.

A measure for the representativity of the mean currents is their directional stability $s$. It is the ratio of the magnitude of the mean vector to the mean speed [Dickson et al., 1985]. A unidirectional flow provides $s=1$, whereas for a drifter in an idealized eddy $s=0$. Figure 7 shows its horizontal distribution in percent. The mean directional stability is $35 \%$. High values can be found in the EGC/WGC region. East of Cape Farewell $80 \%$ are exceeded. This also holds for the NEC west of $40^{\circ} \mathrm{W}$. The NAC has values between $30 \%$ and $45 \%$ and in the $\mathrm{AC}$ region, $s$ varies between $20 \%$ and $50 \%$. Minima are situated in the centers of the subpolar and the subtropical gyre, in the separation zone between NAC and IC and south of the Azores. In these areas, $s$ is less than $20 \%$, sometimes less than $10 \%$.

Because the mean velocity field derived above (Figure 6a) is not perfect and contains information from one layer only, the existence of a divergent flow component cannot be excluded. In order to investigate the degree of divergence of the mean velocity field, the velocity stream function was calculated by means of an objective analysis technique yielding a nondivergent field [Apel, 1987; Bretherton et al., 1976]. The resulting stream function is depicted in Figure 8. It reproduces all important features discussed before so that one can expect that the nondivergent portion clearly dominates the mean circulation. This is confirmed by a comparison of the nondivergent part with the divergent part. From the stream function $\Psi$ the nondivergent zonal and meridional velocity components $u$ and $v$ were obtained by using central differences and the relations

$$
u=-\frac{\delta \Psi}{\delta y} ; \quad v=\frac{\delta \Psi}{\delta x}
$$

The resulting mean velocity vectors are shown in Figure 9a. Subtraction of these vectors from the original mean vectors (Figure 6a) provided the divergent portion of the mean velocity field depicted in Figure $9 \mathrm{~b}$. It is clearly visible that the nondivergent part is very similar to the original vector field and that the vectors of the divergent part are considerably smaller in magnitude and totally uncorrelated, giving the impression that they are noise. Hence the mean velocity field can be regarded to a reasonable degree as nondivergent, supporting its reliability.

\section{Energy Distribution and Lateral Energy Transfer}

For our analysis we divided the total kinetic energy into three parts: (1) kinetic energy of the mean circulation (KEM),

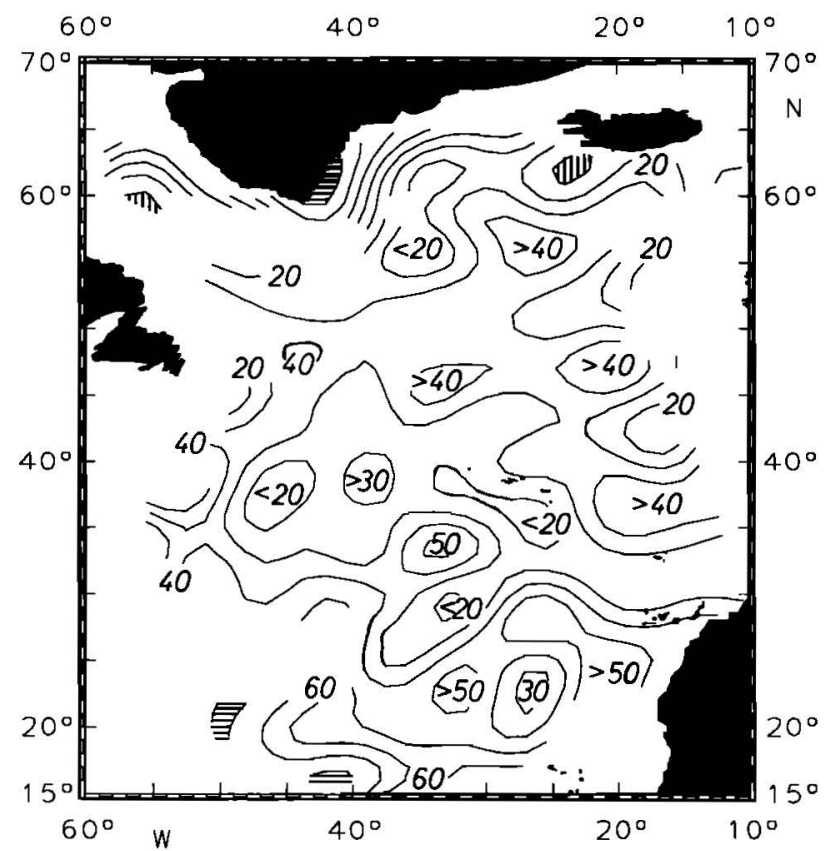

Figure 7. Horizontal distribution of the directional stability $s$ (percent). Contour interval is $10 \%$. Areas $>80 \%$ are horizontally hatched, and areas $<10 \%$ are vertically hatched. 


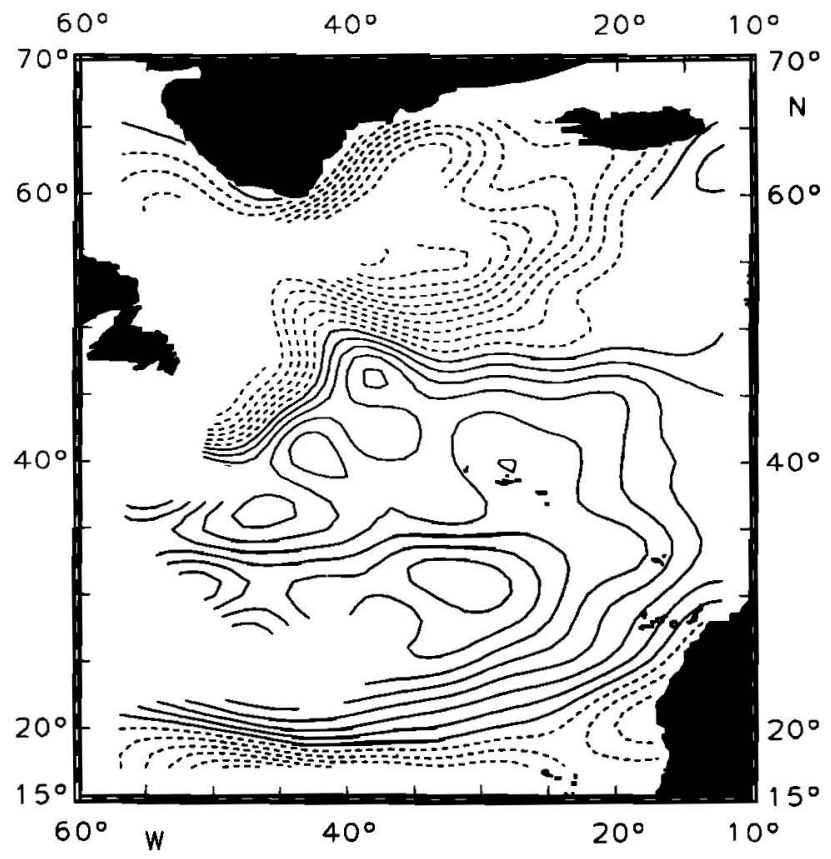

Figure 8. Stream function of the mean velocity field (anomaly field). Contour interval is $5000 \mathrm{~m}^{2} / \mathrm{s}$. Negative values are dashed.

(2) eddy kinetic energy (EKE), and (3) high-frequency part of the kinetic energy (EHFQ). KEM generally represents the energy of the large scale, (almost) stationary circulation and is here directly associated with the mean drift velocities discussed above. EKE and EHFQ result from the fluctuating parts of the velocity. Following Schmitz [1977] we define EKE as the kinetic energy of all velocity fluctuations with periods greater than 1 day. Consequently, EHFQ comprises the kinetic energy of all velocity fluctuations with periods less than 1 day. This part mainly comprises tidal and inertial motions. The boundary between EKE and EHFQ, that is, the EKE frequency range, is not uniformly determined. Hence in many investigations of the mesoscale variability based on drifter data, EHFQ was not analyzed or combined with EKE [e.g., Piola et al., 1987; Daniault and Menard, 1985; Poulain and Niiler, 1989].

The contribution of these different energy "types" to the total kinetic energy varies considerably in space. EKE dominates in most areas of the North Atlantic. On the basis of ship drift data Wyrtki et al. [1976] found EKE/KEM ratios ranging from 20 to 40 in most regions, only in the Gulf Stream area do ratios $<1$ occur. The EKE dominance is also manifest in data from moored current meters and drifter data. Dickson [1983] found ratios $<1$ at just a few locations, whereas in almost the entire region the ratio is $>1$ or $\gg 1$, and Richardson [1983] reports ratios between 2 in the NEC and 37 in the Antilles Current.

Figure 10 shows the KEM distribution. Of course, it contains the same information as the mean velocity field in Figure 6a, but this kind of presentation is more suitable to a quantitative comparison with other results. Regions with values exceeding $50 \mathrm{~cm}^{2} / \mathrm{s}^{2}$ exist only northwest of the line $30^{\circ} \mathrm{N}, 50^{\circ} \mathrm{W}-55^{\circ} \mathrm{N}$, $15^{\circ} \mathrm{W}$ and in the western part of the NEC. Maximum values are associated with the NAC and the EGC/WGC regime, where $220 \mathrm{~cm}^{2} / \mathrm{s}^{2}$ are reached off Cape Farewell. As in the vector plot (Figure 6a) the occasional branching of the NAC at about $47^{\circ} \mathrm{N}, 40^{\circ} \mathrm{W}$ can be seen in the structure of the KEM distribution. Local maxima in the eastern part of the subtropical gyre indicate the position of the $\mathrm{AC}$ and the $\mathrm{CC}$, respectively. The lowest values occur south of the Azores where KEM approaches zero.

Wyrtki et al. [1976, Figure 1] deduced a KEM distribution, based on historical ship drift data. It agrees well with this analysis in the NAC area but shows discrepancies in other regions. In the eastern part of the NEC their map shows values of about $100 \mathrm{~cm}^{2} / \mathrm{s}^{2}$ which are considerably higher than those obtained in the present analysis. On the other hand, the ship drift data produce a smaller KEM level of about $10 \mathrm{~cm}^{2} / \mathrm{s}^{2}$
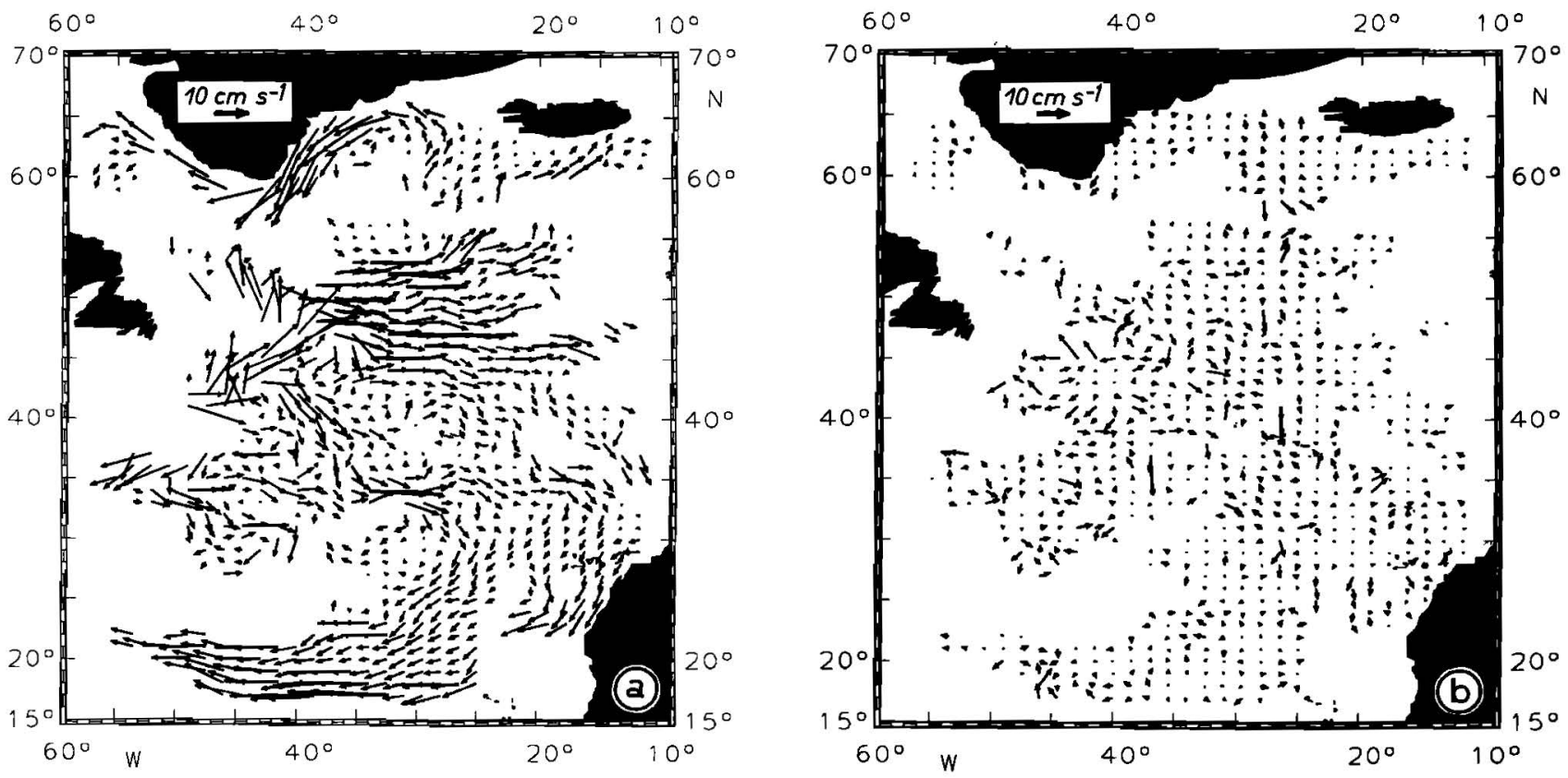

Figure 9. (a) Nondivergent part and (b) divergent part of the mean velocity field (Figure 6a). 


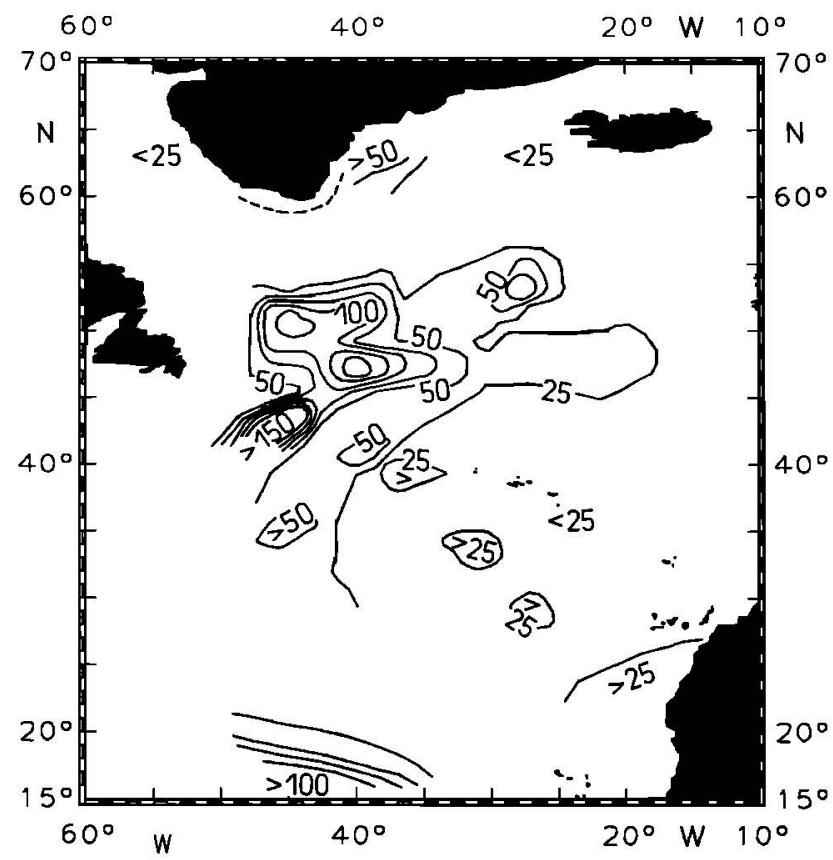

Figure 10. Distribution of the kinetic energy of the mean velocity (KEM). Contour interval is $25 \mathrm{~cm}^{2} / \mathrm{s}^{2}$. The dashed line marks a region at Cape Farewell with values exceeding 150 $\mathrm{cm}^{2} / \mathrm{s}^{2}$.

southeast of the NAC where the drifter analysis provides values up to $50 \mathrm{~cm}^{2} / \mathrm{s}^{2}$. In addition, no indication for the $A C$ is visible. These differences are because of the influence of the wind on the ship's drift. In the NEC area the trade winds blow very constantly and parallel to the ocean currents, leading to an overestimation of the mean current velocities. The opposite holds for the region north of the NEC because of the very variable winds.

In most regions, EKE provides the largest kinetic energy portion. Because of its dominance a good knowledge of this principal parameter is important for several reasons: (1) EKE distributions give information about the ocean dynamics, that is, help to identify energy sources, sinks, and advection paths; (2) in some regions with a high EKE level, EKE is regarded as a forcing of the mean circulation [Holland et al., 1983; Böning and Budich, 1992]; and (3) measured EKE fields are suited for a verification of eddy resolving ocean model results and hence may contribute to their improvement [Beckmann et al., 1994b]. Figure 11 shows the EKE distribution from this analysis. We find very high values in the vicinity of the NAC. A tongue with values exceeding $1000 \mathrm{~cm}^{2} / \mathrm{s}^{2}$ extends in the northeast direction from $40^{\circ} \mathrm{N}, 50^{\circ} \mathrm{W}$ to $50^{\circ} \mathrm{N}, 40^{\circ} \mathrm{W}$. The absolute EKE maximum with $1426 \mathrm{~cm}^{2} / \mathrm{s}^{2}$ is located at $41^{\circ} \mathrm{N}, 48^{\circ} \mathrm{W}$ in the Gulf Stream extension. In the southeast direction EKE decreases very rapidly to values $<100 \mathrm{~cm}^{2} / \mathrm{s}^{2}$ in the subtropical gyre outside the CC. Strong gradients also exist toward the American shelf and the subpolar gyre.

The outstanding information of the EKE distribution is that EKE is concentrated along the main currents which therefore determine its distribution. The signal associated with the NAC also dominates the northeastern part of the distribution. There the $300 \mathrm{~cm}^{2} / \mathrm{s}^{2}$ isoline extends to about $22^{\circ} \mathrm{W}$. An other "nose" in the eastern part of the distribution is produced by the $\mathrm{AC}$, recognizable by the $100 \mathrm{~cm}^{2} / \mathrm{s}^{2}$ isoline along about $35^{\circ} \mathrm{N}$. Its location coincides well with satellite altimetry observations
[Tokmakian and Challenor, 1993]. Other local maxima exist in the EGC/WGC and the CC area. Regions with low EKE levels separate the current regimes. We observe typical values of about $50 \mathrm{~cm}^{2} / \mathrm{s}^{2}$ which can decrease to $10 \mathrm{~cm}^{2} / \mathrm{s}^{2}$ in the area between the NAC and the AC signal. The NEC does not produce a local EKE maximum, indicating a composition of its total kinetic energy different from that in the NAC and AC region. This will be discussed later.

The first basin wide EKE distribution for the North Atlantic was presented by Wyrtki et al. [1976]. In their map, EKE maxima are concentrated along the western boundary currents and in the tropics. Nevertheless, the corresponding spatial distribution is more homogeneous than our results indicate, in the GS/NAC region only $400-800 \mathrm{~cm}^{2} / \mathrm{s}^{2}$ are reached, whereas in the eastern part $400 \mathrm{~cm}^{2} / \mathrm{s}^{2}$ are observed. A distinct $A C$ signal is not detectable. The reasons for these quantitative discrepancies have already been discussed by Richardson [1983]: the underestimation in regions with high-energy level is because of the use of an averaging length of about $400 \mathrm{~km}$ which is larger than the typical horizontal scales of the currents and the overestimation in low EKE level regions is produced by inaccuracies in ship drift velocity determinations.

Dantzler [1977] and Emery [1983] provided maps of the available potential energy (EPE) from expendable bathythermograph (XBT) measurements. Of course, EPE and EKE are not the same, but both parameters are closely coupled by the mechanism of baroclinic instability [Böning and Budich, 1992; Beckmann et al., 1994b]. Emery's map of the temperature standard deviation in 400-m depth is qualitatively in good agreement with our EKE distribution: the largest temperature variabilities occur in the GS/NAC band and an AC signal is visible, too.

Up to now, the only large scale EKE chart which was based on drifter data independent from the Kiel data set was the analysis performed by Richardson [1983]. It is depicted in Figure 12 (his Figure 10). Additionally, the corresponding contour

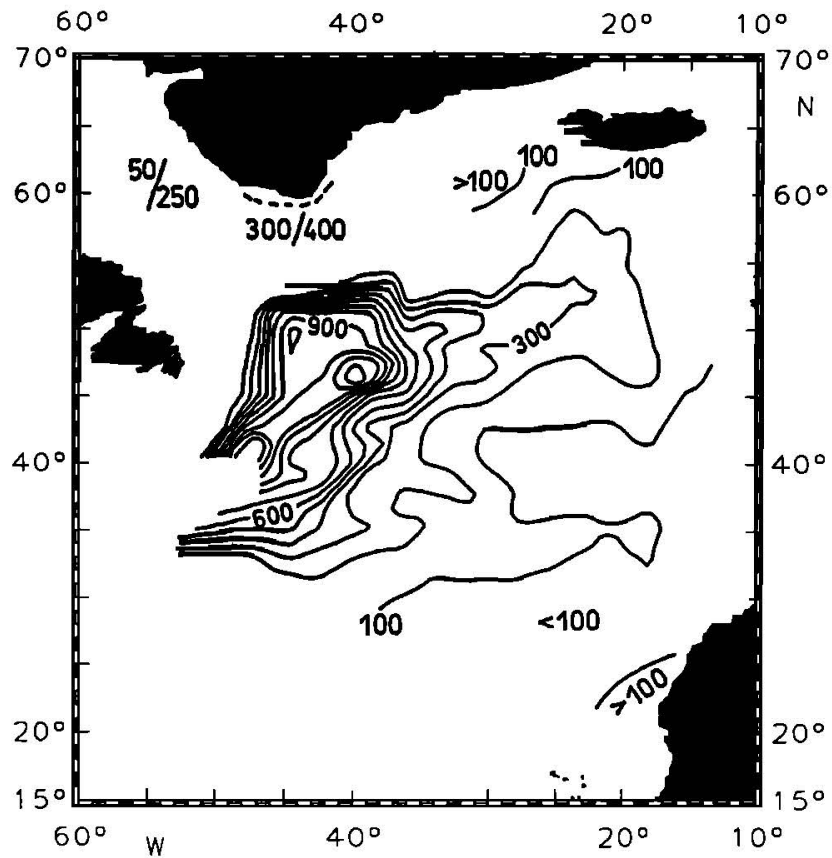

Figure 11. Distribution of the eddy kinetic energy (EKE). Contour interval is $100 \mathrm{~cm}^{2} / \mathrm{s}^{2}$. The dashed line marks a region at Cape Farewell with values exceeding $400 \mathrm{~cm}^{2} / \mathrm{s}^{2}$. 


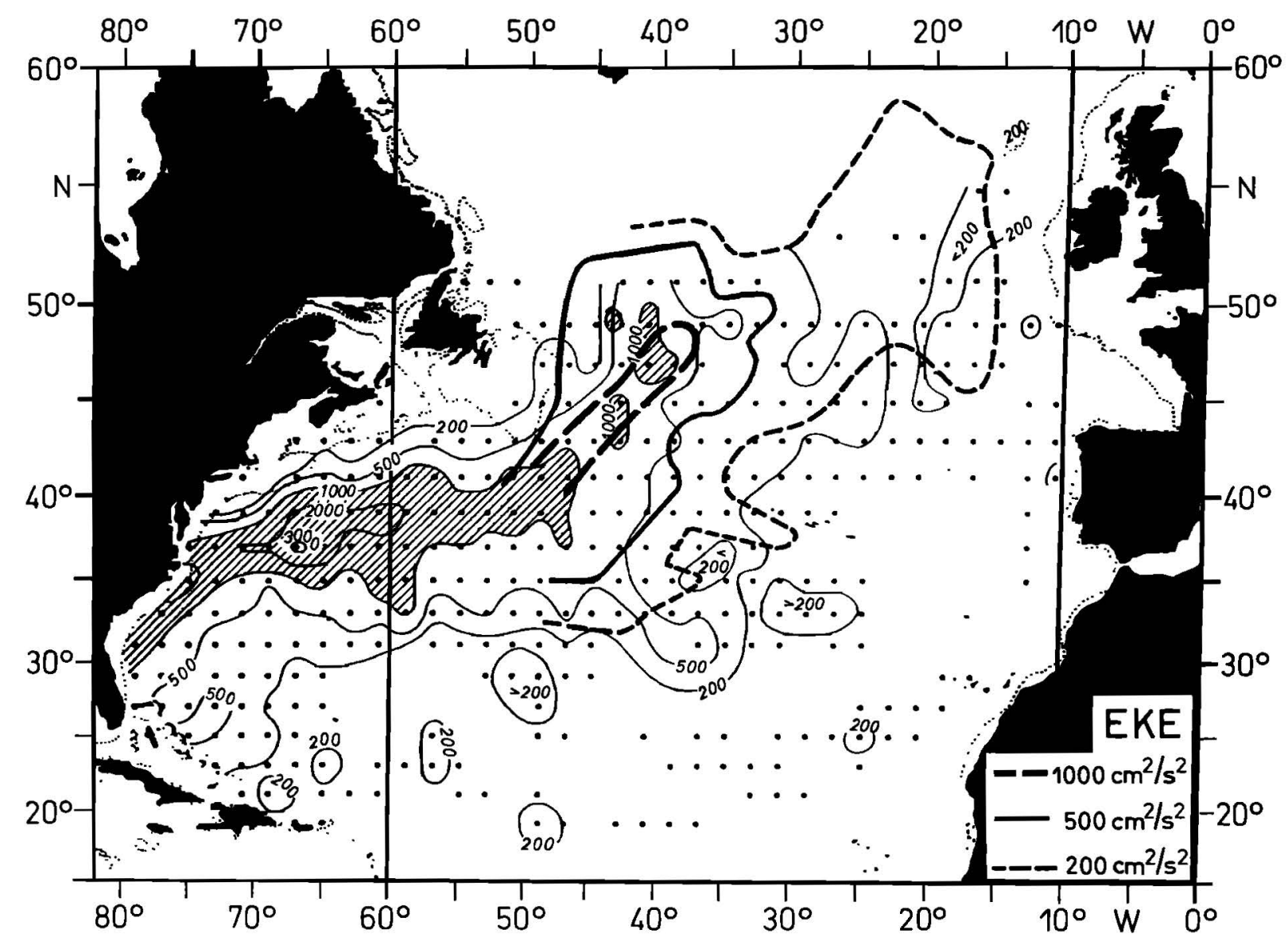

Figure 12. EKE distribution deduced by Richardson [1983, Figure 10]. The 1000 , 500, and $200 \mathrm{~cm}^{2} / \mathrm{s}^{2}$ contour lines of this analysis are added. Vertical lines indicate the area common for both investigations.

lines of this paper were drawn into the map. Differences between both maps can be expected because the buoys compiled for the data sets had different drogue states. Most of the buoys used by Richardson were drogued in the mixed layer; some buoys were deployed without a drogue. In addition, it is very likely that they had already lost their drogues when they entered the eastern and subtropical part of the North Atlantic several months after their deployment in the GS. An inspection of the $500 \mathrm{~cm}^{2} / \mathrm{s}^{2}$ contours reveals that the area with high EKE values west of the EKE maxima is much more concentrated at the NAC core in Richardson's chart. Areas with larger differences also exist south of about $35^{\circ} \mathrm{N}$ in the vicinity of the $\mathrm{AC}$, where the EKE level in his map is considerably higher than in our map. In that region the decreasing data density in Richardson's data set may have influenced the results, too. On the other hand, the positions of the $1000 \mathrm{~cm}^{2} / \mathrm{s}^{2}$ isolines are in good agreement, indicating that there is no significant difference in the NAC core. These results coincide with those of Brugge and Dengg [1991]. They showed that in areas with very strong currents (like the NAC core) the state of the drogue is not so important because the force of the current acting on the buoy is much stronger than the force of the wind. The opposite holds for regions with weak currents. There the knowledge about the drogue's state is essential in order to get reliable analysis results. In agreement with the results of Colin de Verdiere [1983] and Krauss and Boning [1987] this analysis confirms that EKE is isotropic [Brügge, 1993].

The distribution of the high-frequency part of the total ki- netic energy is shown in Figure 13. It is dominated by a tongue with high values extending from $55^{\circ} \mathrm{N}, 50^{\circ} \mathrm{W}$ to the Azores. The tongue contains local maxima north of Flemish Cap $(>75$ $\left.\mathrm{cm}^{2} / \mathrm{s}^{2}\right)$ and north of the Azores $\left(>50 \mathrm{~cm}^{2} / \mathrm{s}^{2}\right)$. Outside the tongue, values $>25 \mathrm{~cm}^{2} / \mathrm{s}^{2}$ can be observed only in the vicinity of the Rockall Plateau, in the western part of the NEC, and at the Iceland-Faroe Ridge where the absolute maximum exceeding $100 \mathrm{~cm}^{2} / \mathrm{s}^{2}$ is located. In the other areas of the central North Atlantic, values between 5 and $25 \mathrm{~cm}^{2} / \mathrm{s}^{2}$ can be found. Inspection of drifter spectra revealed that energy from inertial motions provides the prevailing part of EHFQ [Brügge, 1993]. In order to arrive at a basin wide map of the inertial energy, a modified complex demodulation technique similar to that used by Poulain [1990] was applied to the data. The result is presented in Figure 14. As can be seen, the distribution is very patchy. Inertial energy ranges from 2 to $120 \mathrm{~cm}^{2} / \mathrm{s}^{2}$, but in most parts of the investigation area the values do not exceed $20 \mathrm{~cm}^{2} / \mathrm{s}^{2}$. An interpretation of this chart (and also of the EHFQ map) is more difficult than an interpretation of the KEM and EKE map. There is no obvious relationship to the mean circulation. It is also not possible to explain the structure solely by the influence of the wind in conjunction with the mixed layer depth. A comparison with the wind stress climatology of Isemer and Hasse [1987] reveals that indeed most of the inertial energy values exceeding $20 \mathrm{~cm}^{2} / \mathrm{s}^{2}$ are situated in areas of large wind stress, but there are also high inertial energies in regions of low wind stress and vice versa. A separation of the data by summer and winter seasons (not shown here) demonstrated 


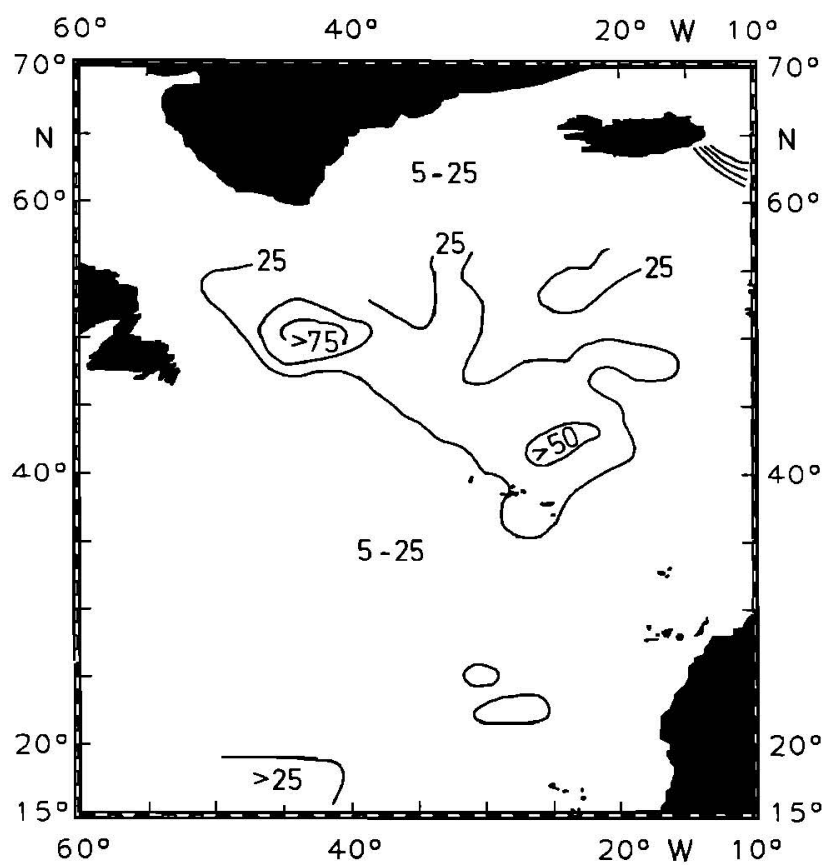

Figure 13. Distribution of the high-frequency part of the kinetic energy (EHFQ). Contour interval is $25 \mathrm{~cm}^{2} / \mathrm{s}^{2}$.

that because of the stronger wind stress and the seasonal deepening of the mixed layer the inertial energy is generally larger in winter than in summer, but the positions of the local maxima remained the same. Because of the fact that the positions of the local maxima are all situated in areas with large gradients in the bottom topography, we believe that the bottom topography plays an important role. However, further analysis is necessary to prove this hypothesis.

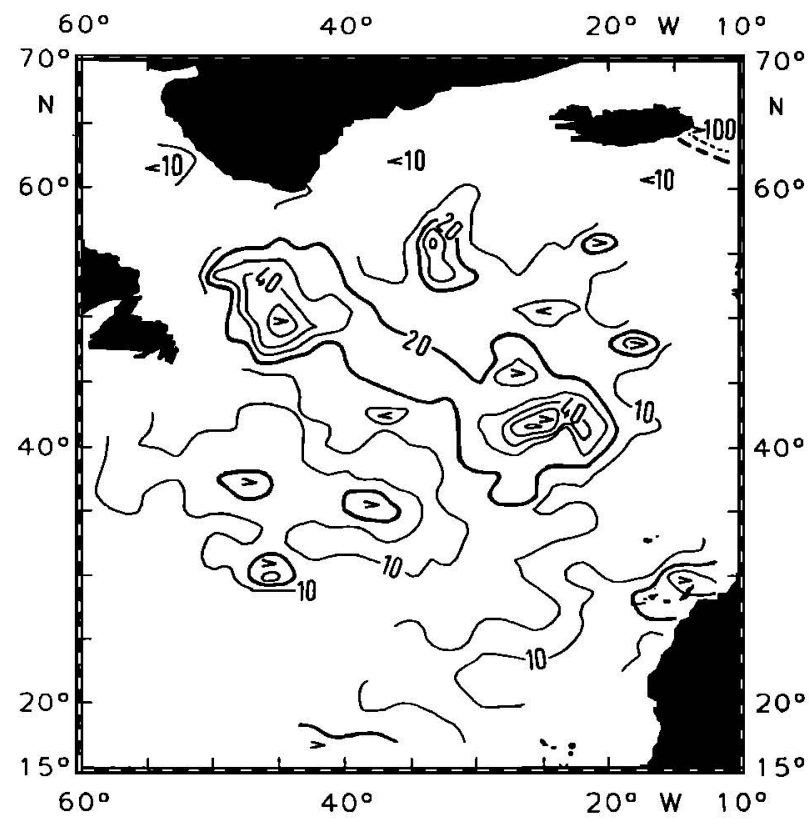

Figure 14. Distribution of the energy of the inertial motions. Contour interval is $10 \mathrm{~cm}^{2} / \mathrm{s}^{2}$. The $20 \mathrm{~cm}^{2} / \mathrm{s}^{2}$ contour is emphasized by bold lines; the dashed lines indicate an area with values exceeding $100 \mathrm{~cm}^{2} / \mathrm{s}^{2}$.

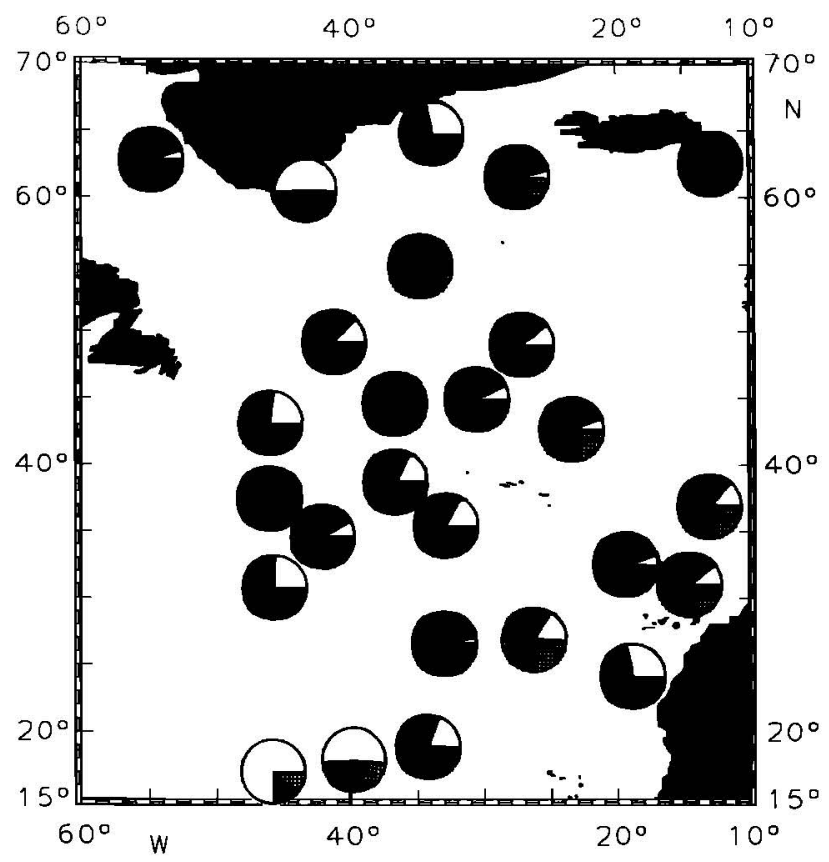

Figure 15. Pie chart of the total kinetic energy portions for selected locations which are representative for their surroundings. A whole pie represents $100 \%$ of the total kinetic energy. The EKE portion is depicted in black, the KEM portion is depicted in white, and the EHFQ portion is hatched.

It was already stated that EKE is the main contributor to the total kinetic energy. On the basin average, EKE accounts for $74 \%$, whereas KEM and EHFQ provide $13.2 \%$ and $12.8 \%$ of the total kinetic energy, respectively. However, there are considerable regional differences. Figure 15 shows the total kinetic energy portions for selected locations which are representative for their surroundings. Highest EKE portions up to $>95 \%$ can be found in the Gulf Stream extension. EKE also clearly dominates the NAC and the $\mathrm{AC}$ region and the central part of the investigation area. EHFQ gains relative importance chiefly in the eastern part of the subtropical gyre in regions with low-EKE level. There the EHFQ portion can rise up to $50 \%$. Largest $\mathrm{KEM}$ portions, with more than $50 \%$, can be observed in the Greenland Current and in the western part of the NEC where $75 \%$ is reached. EKE/KEM ratios reveal a basin wide average of 5.6 varying between 0.2 in the NEC and 8900 in the Gulf Stream extension.

How do KEM and EKE fields interact? The nature of Lagrangian data does not allow the calculation of a complete energy budget. We therefore concentrate on the question whether the turbulent momentum fluxes, caused by the horizontal shear of the mean circulation, transfer energy from the mean field to the eddy field or vice versa. Similar analyses of the Reynolds stress term have been performed at several positions in the Florida Current and the GS based on geoelectrokinetograph data [Webster, 1965], drop sonde data [Brooks and Niiler, 1977], moorings [Schmitz, 1977], and Pegasus data [Rossby, 1987]. They generally showed that there is a turbulent energy transfer from the eddy field to the mean circulation. These measurements were confirmed by the results of an idealized box model of the North Atlantic [Böning and Budich, 1992].

In order to investigate whether this behavior is also valid in the NAC area, the KEM-EKE interaction term $\overline{u_{i}}\left(\delta / \delta x_{j}\right) \overline{u_{t} u_{J}}$ [Harrison and Robinson, 1978] was calculated and depicted in 


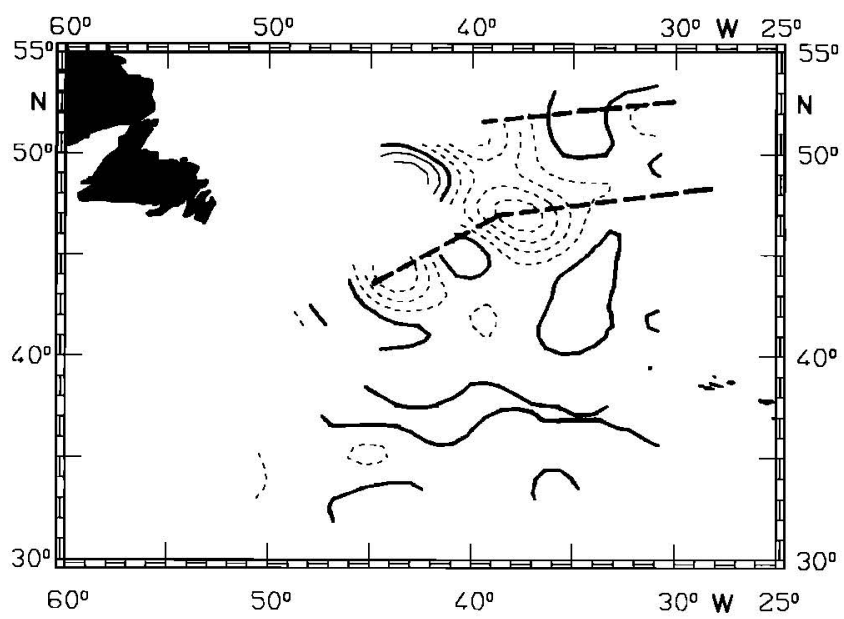

Figure 16. Distribution of the KEM-EKE interaction term $\bar{u}_{\imath}\left(\delta / \delta x_{j}\right) \overline{u_{\imath}^{\prime} u_{j}^{\prime}}$. Contour interval is $10^{-4} \mathrm{~cm}^{2} / \mathrm{s}^{3}$. The zero contour is emphasized by bold lines. Dashed lines indicate the path of the NAC.

Figure 16 . The path of the NAC is schematically presented by the bold dashed lines. South of the NAC the values are too small and noisy to be significant. However, the large negative values in the vicinity of the NAC indicate an energy transfer from the eddy field to the mean velocity field. This is in agreement with the observations in the Florida Current and in the Gulf Stream showing that the Reynolds stress term does not change its behavior in the western boundary current regime. The magnitude of the lateral energy transfer would imply a KEM doubling time of less than 10 days due to this process. In reality, this KEM increase is compensated by baroclinic instability processes.

\section{Summary and Conclusions}

The objective of this paper is a self-contained presentation of the near-surface mean circulation and its variability in the central North Atlantic. Knowledge of these statistical properties is necessary for understanding the dynamics and implication of fluctuations in the ocean. In particular, it can be a useful tool for the verification and improvement of eddy-resolving ocean models. It is the first large-scale analysis that is based on a corrected drifting buoy data set, that is, all data from buoys without drogue were eliminated and all remaining drifters have the same drogue depth $(100 \mathrm{~m})$.

The physical parameters were deduced by averaging the data in $2^{\circ} \times 3^{\circ}$ boxes. An empirical quality criterion was used to determine the minimum amount of data necessary to get statistically (almost) stable results. The number depends on the variance of the velocity field, that is, on the kinetic energy level. This has an important implication for current measurements with drifting buoys. They should be deployed in regions of high kinetic energy because more data are needed there to get reliable results than in areas with low kinetic energy. In addition, drifting buoys normally move from high- to low-energy regions. The combination of the data set correction and our quality criterion improves the reliability of our analysis considerably.

The mean velocity field reproduces all important currents in the investigation area. Mean velocities greater than $20 \mathrm{~cm} / \mathrm{s}$ can be found in the core of the NAC and in the EGC. EGC and NEC appear as regions with very high directional stability. Compared to climatologies based on the Levitus data set $[\mathrm{Ol}$ - bers et al., 1985], this analysis provides a better resolution of the circulation structure. On the other hand, the picture is incomplete, especially in the eastern part of the Atlantic. In contrast to the work by Schmitz and McCartney [1993], no indication supporting Worthington's "two gyre" hypothesis can be found. The drifter data show that the NAC is the direct continuation of the GS to the north. A stream function approach was used to separate the mean velocity field into a divergent and a nondivergent part, revealing that the mean field can be regarded as almost nondivergent.

Eddy kinetic energy is distributed very inhomogeneously. It is isotropic and concentrated along the mean currents. There is a good qualitative agreement with similar maps deduced from satellite altimetry [e.g. Stammer and Böning, 1992; Shum et al., 1990]. A quantitative comparison with distributions originating from measurements with other systems must be treated with care because they normally record different spatial and temporal scales of the variability. Because of the data density and the precautions concerning the data quality our EKE map seems to be more reliable east of $45^{\circ} \mathrm{W}$ than the map compiled by Richardson [1983].

Among others, Beckmann et al. [1994a] showed that EKE distributions produced by present eddy-resolving models have substantial qualitative and quantitative errors. The close coupling between EKE and the mean currents found in the drifter data suggests that improvements of the model mean circulation will also improve the EKE distribution, at least qualitatively. This could lead to more realistic model results. We believe that the improvement of models will become more and more important because it is not possible to arrive at a complete three-dimensional picture of the current field in the North Atlantic with measurements only.

EKE provides the largest portion of the total kinetic energy. The basin average is $74 \%$; the rest is equally distributed between KEM and EHFQ. Largest regional variations occur in the EGC and NEC regime where the KEM portion can rise up to $75 \%$ and in the eastern part of the subtropical gyre where the EHFQ portion gains relative importance. EHFQ mainly consists of energy from inertial motions. The deduced inertial energy map is very patchy. There are indications that, besides wind field and mixed layer depth, the bottom topography has an influence on the distribution.

Reynolds stress term analysis reveals an energy transfer from the eddy field to the mean circulation in the vicinity of the NAC. Independent investigations in the Kuroshio area, based on XBT and conductivity-temperature-depth data [Nishida and White, 1982], moorings [Schmitz et al., 1982], and altimeter data [Tai and White, 1990], as well as in the Antarctic Circumpolar Current with altimeter data [Johnson et al., 1992] gave similar results. It might therefore be that this kind of energy transfer is a common property of all well-defined currents. But this has to be proved in the future.

Acknowledgments. I would like to thank W. Krauss, A. Beckmann, and H. H. Hinrichsen for helpful discussions and A. Schurbohm for assistance in preparing the plots. This study was supported by the Deutsche Forschungsgemeinschaft (DFG Sonderforschungsbereich SFB 133).

\section{References}

Apel, J. R., Principles of Ocean Physics, 631 pp. Academic, San Diego, Calif., 1987.

Arhan, M., The North Atlantic Current and Subarctic Intermediate Water, J. Mar. Res., 48, 109-144, 1990.

Beckmann, A., C. W. Boning, C. Koberle, and J. Willebrand, Effects of 
increased horizontal resolution in a simulation of the North Atlantic Ocean, J. Phys. Oceanogr., 24, 326-344, 1994a.

Beckmann, A., C. W. Boning, B. Brugge, and D. Stammer, Eddy variability in the central North Atlantic Ocean, J. Geophys. Res., 99, 20,381-20,391, 1994b.

Bönıng, C. W., and R. G. Budich, Eddy dynamics in a primitıve equation model: Sensitivity to horizontal resolution and friction, J. Phys. Oceanogr., 22, 361-381, 1992.

Bretherton, F., R. Davis, and C. Fandry, A technique for objective analysis and design of oceanographic experiments applied to MODE-73, Deep Sea Res., 23, 559-582, 1976.

Brooks, I. H., and P. P. Niiler, Energetics of the Florida Current, J. Mar Res., 35, 163-191, 1977.

Brügge, B., Uber die Eigenschaften der oberflachennahen Zirkulation im zentralen Nordatlantik, Ph.D. dissertation, 131 pp., Univ. of Kiel, Kiel, Germany, 1993.

Brugge, B., and J. Dengg, Differences in drift behavior between drogued and undrogued satellite-tracked drifting buoys, J. Geophys. Res., 96, 7249-7263, 1991.

Clarke, R. A., H. W. Hill, R. F. Reiniger, and B. Warren, Current systems south and east of the Grand Banks of Newfoundland, $J$. Phys. Oceanogr., 10, 25-65, 1980.

Colin de Verdiere, A., Lagrangian eddy statistics from surface drifters in the eastern North Atlantic, J. Mar. Res., 41, 375-398, 1983.

Daniault, N., and Y. Menard, Eddy kinetic energy distribution in the southern ocean from altimetry and FGGE drifting buoys, $J$. Geophys. Res., 90, 11,877-11,889, 1985.

Dantzler, H. L. Jr., Potential energy maxima in the tropical and subtropical North Atlantic, J. Phys Oceanogr., 7, 512-519, 1977.

Davis, R. E., Observing the general circulation with floats, Deep Sea Res., Part A, 38, S531-S571, 1991.

Dickson, R. R., Global summaries and intercomparisons: Flow statistics from long-term current meter moorings, in Eddies in Marine Sciences, edited by A. R. Robınson, pp. 278-353, Springer-Verlag, New York, 1983.

Dickson, R. R., W J. Gould, T. J. Müller, and C. Maillard, Estimates of the mean circulation in the deep $(>2000) \mathrm{m})$ layer of the eastern North Atlantic, Prog. Occanogr., 14, 103-127, 1985.

Dietrich, G., K. Kalle, W. Krauss, und G. Siedler, Allgemeine Meereskunde, 593 pp., Gebruder Borntrager, Berlin, 1975.

Emery, W. J., On the gcographical variability of the upper level mean and eddy fields in the North Atlantic and North Pacific, J. Phys. Oceanogr., 13, 269-291, 1983.

Harrison, D. E., and A. R. Robinson, Energy analysis of open regions of turbulent flows-mean eddy energetics of a numerical ocean circulation experiment, Dyn. Atmos. Oceans, 2, 185-211, 1978.

Holland, W. R., D. E. Harrison, and A. J. Semtner Jr., Eddy-resolving numerical models of large-scalc occan circulation, in Eddies in Marine Sciences, edited by A. R. Robinson, pp. 379-403, SpringerVerlag, New York, 1983.

Isemer, H.-J., and L. Hasse, The Bunker Climate Atlas of the North Atlantic Ocean, vol. 2, Air-Sca Interactions, 256 pp., Springer-Verlag, New York, 1987.

Johnson, T. J., R. H. Stewart, C. K. Shum, and B. D. Tapley, Distribution of Reynolds stress carried by mesoscale variability in the Antarctic Circumpolar Current, Geophys Res. Lett., 19, 1201-1204, 1992.

Klein, B., and G. Siedler, On the origin of the Azores Current, $J$ Geophys. Res., 94, 6159-6168, 1989.

Krauss, W., The North Atlantic Current, J. Geophys. Res., 91, 5061$5074,1986$.

Krauss, W., Currents and mixing in the Irmınger Sea and in the Iceland Basin, J. Geophys Res., 100, 10,851-10,871, 1995a.

Krauss, W., On the slippage of deep-drogued drifters, J. Geophys Res., in press, 1995b.

Krauss, W., and C. W. Boning, Lagrangian properties of eddy fields in the northern North Atlantic as deduced from satellite-tracked buoys, J. Mar. Res., 45, 259-291, 1987.

Krauss, W., and R. H. Kase, Mean circulation and eddy kinetic energy in the eastern North Atlantic, J. Geophys. Res., 89, 3407-3415, 1984.

Krauss, W., J. Dengg, and H.-H. Hinrichsen, The response of drifting buoys to currents and wind, J. Geophys. Res, 94, 3201-3210, 1989.

Krauss, W., E. Fahrbach, A. Aitsam, J. Elken, and P. Koske, The North Atlantic Current and its associated eddy field southeast of Flemish Cap, Deep Sea Res., Part A, 34, 1163-1185, 1987.

Large, W. G., and H. van Loon, Large scale, low frequency variability of the 1979 FGGE surface buoy drifts and winds over the southern hemisphere, J. Phys. Oceanogr., 19, 216-232, 1989.

Mann, C. R., The termination of the Gulf Stream and the beginning of the North Atlantic Current, Deep Sea Res., 14, 337-359, 1967.

Nishida, H., and W. B. White, Horizontal eddy fluxes of momentum and kinetic energy in the near-surface of the Kuroshio Extension, $J$. Phys. Oceanogr., 12, 160-170, 1982.

Olbers, D. J., M. Wenzel, and J. Willebrand, The inference of the North Atlantic circulation patterns from climatological hydrographic data, Rev. Geophys., 23, 313-356, 1985.

Owens, W. B., A statistical description of the mean circulation and eddy variability in the northwestern Atlantic using SOFAR floats, Prog. Oceanogr., 28, 257-303, 1991.

Patterson, S. L., Surface Circulation and Kinetic Energy Distributions in the Southern Hemisphere Oceans from FGGE Drifting Buoys, $J$ Phys Oceanogr., 15, 865-884, 1985.

Piola, A. R., H. A. Figueroa, and A. A. Bianchi, Some aspects of the surface circulation south of $20^{\circ} \mathrm{S}$ revealed by first GARP global experiment drifters, J. Geophys. Res., 92, 5101-5114, 1987.

Poulain, P. M., Near-inertial and diurnal motions in the trajectories of mixed layer drifters, J. Mar. Res., 48, 793-823, 1990.

Poulain, P. M., and P. P. Niiler, Statistical Analysis of the Surface Circulation in the California Current System using Satellite-Tracked Drifters, J. Phys. Oceanogr., 19, 1588-1603, 1989.

Richardson, P. L., Eddy kinetic energy in the North Atlantic from surface drifters, J. Geophys. Res., 88, 4355-4367, 1983.

Rossby, T., On the energetics of the Gulf Stream at 73W, J. Mar. Res., $45,59-82,1987$.

Schmitz, W. J., Jr., On the deep general circulation in the western North Atlantic, J Mar. Res., 35, 21-28, 1977.

Schmitz, W. J., Jr., and M. S. McCartney, On the North Atlantic circulation, Rev. Geophys., 31, 29-49, 1993.

Schmitz, W. J., Jr., P. P. Niiler, R. L. Bernstein, and W. R. Holland, Recent long-term moored instrument observations in the western North Pacific, J. Geophys. Res., 87, 9425-9440, 1982.

Schott, G., Geographie des Atlantischen Ozeans, 438 pp., C. Boysen, Hamburg, Germany, 1944.

Shum, C. K., R. A. Werner, D. T. Sandwell, B. H. Zhang, R. S. Nerem, and B. D. Tapley, Variations of global mesoscale eddy energy observed from Geosat, J. Geophys. Res., 95, 17,865-17,876, 1990.

Stammer, D., and C. W. Böning, Mesoscale variability in the Atlantic Ocean from Geosat altimetry and WOCE high-resolution numerical modelling effort, J. Phys. Oceanogr., 22, 732-752, 1992.

Sverdrup, H. U., M. W. Johnson, and R. H. Fleming, The oceans, their physics, chemistry, and general biology, 1087 pp., Prentice-Hall, Englewood Cliffs, N. J., 1942.

Sy, A., Untersuchungen zum großskaligen Feld der Zirkulation des Nordatlantiks im Bereich des Mittelatlantischen Ruckens, Ph.D. dissertation, 194 pp., Univ. of Hamburg, Hamburg, Germany, 1987.

Sy, A., Investigation of large-scale circulation patterns in the central North Atlantic: The North Atlantic Current, the Azores Current, and the Mediterranean Water plume in the area of the Mid-Atlantic Ridge, Deep Sea Res., Part A, 35, 383-413, 1988.

Sy, A., U. Schauer, and J. Meincke, The North Atlantic Current and its associated hydrographic structure above and eastward of the midAtlantic Ridge, Deep Sea Res., Part A, 39, 825-853, 1992.

Tai, C.-K., and W. B. White, Eddy variability in the Kuroshio Extension as revealed by Geosat altimetry: Energy propagation away from the jet, Reynolds stress, and seasonal cycle, J. Phys. Oceanogr., 20, 1761-1777, 1990.

Tokmakian, R. T., and P. G. Challenor, Observations in the Canary Basin and the Azores Frontal Region using Geosat data, J. Geophys. Res., 98, 4761-4773, 1993.

Webster, F., Measurements of eddy fluxes of momentum in the surface layer of the Gulf Stream, Tellus, 17, 239-245, 1965.

Worthington, L. V., On the North Atlantic Circulation, Oceanogr. Stud., 6, 1-110, 1976.

Wyrtki, K., L. Magaard, and J. Hager, Eddy energy in the oceans, $J$. Geophys. Res., 81, 2641-2646, 1976.

B. Brugge, Institut für Meereskunde, Dusternbrooker Weg 20, D-24105 Kiel, Germany. (e-mail: bbruegge@ifm.uni-kiel.d400.de)

(Received June 20, 1994; revised February 2, 1995;

accepted March 7, 1995.) 